\title{
Early Development of Endoscopic Endonasal Pituitary and Skull Base Surgery
}

\author{
Diana H Jho ${ }^{2}$, David H Jho ${ }^{1}$ and Hae-Dong Jho*1 \\ ${ }_{1}^{1}$ Jho Institute for Minimally Invasive Neurosurgery, Department of Neuroendoscopy, Neuroscience Institute, Allegheny General Hospital, Drexel University \\ College of Medicine, Pittsburgh, Pennsylvania
}

${ }^{2}$ Department of Neurosurgery, Penn State Health Milton S. Hershey Medical Center, Penn State University College of Medicine, Hershey, Pennsylvania

Submission: April 17, 2018; Published: May 10, 2018

*Corresponding author: Hae-Dong Jho, Jho Institute for Minimally Invasive Neurosurgery, Department of Neuroendoscopy, Neuroscience Institute, Allegheny General Hospital, Drexel University College of Medicine, Pittsburgh, Pennsylvania, Tel: 412-359-6110; Email: DrJho@DrJho.com

\begin{abstract}
The endoscopic endonasal approach to the pituitary and skull base was explored in the early 1990's when endoscopic sinus surgery had already been well established by otolaryngologists. HDJho initiated a cadaveric study in 1991 followed by clinical application on patients in collaboration with an otolaryngologist skull base surgeon, Ricardo Carrau in 1993. Subsequently, Jho and Carrau reported the first significant number of clinical cases, but attempts at publication were unexpectedly delayed due to disinterest from major neurosurgery journals until 1996. The first publication was made possible by an otolaryngology journal, Laryngoscope. Only then, did neurosurgery journals begin to take interest. Once the endoscopic endonasal approach to pituitary pathologies was developed, Jho and Carrau soon discovered an easily accessible corridor to a wide range of midline skull base lesions from the crita galli to the craniocervical junction. Soon, endoscopic endonasal technique was being utilized for surgery for the optic nerve, anterior cranial skull base, cavernous sinus, pterygoid fossa, petrous tip, middle cranial fossa, clivus, and craniocervical junction. Early case series of the endoscopic endonasal approach to the anterior cranial fossa, cavernous sinus, and clivus were submitted in three separate papers respectively and accepted in 1997, but actual publication was delayed by publisher's oversight until 2004. Reported herein is the early development of the endoscopic endonasal approach to the pituitary and skull base by the senior author during his time at the University of Pittsburgh Medical Center in the 1990's.
\end{abstract}

Keywords: Acromegaly; Cushing's disease; Pituitary adenoma; Pituitary gland; Prolactinoma; Endoscopic transsphenoidal surgery

\section{Introduction}

Although the utilization of an endoscope in brain surgery was started more than a century ago [1], the clinical use of an endoscope in pituitary surgery was not practical until sinonasal endoscopy was fully established and commonly utilized in the 1990 's by the otolaryngologists [2,3]. The initial use of sinonasal endoscopy began in Europe half a century ago. Its introduction to the United States four decades ago sparked an evolution in sinonasal surgical techniques. In addition, the transsphenoidal approach for pituitary tumors was revived with the development of microscopic surgery in the 1970's after being abandoned by Cushing in preference for the transcranial route in the early 1900's [4]. With the evolution of technology, the sublabial transseptal route progressively transformed to an endonasal route $[5,6]$.

HD Jho explored the use of an endoscope in endonasal transphenoidal surgery in cadavers in 1991 and subsequently adopted it to clinical patient care with an otolaryngologist skull base surgeon, Ricardo Carrau, in September of 1993 [7-21]. The physique of the endoscope with the slender shaft and optics at the tip allowed for easy access to the sella through the natural nasal air pathway via the nostrils. The wide-angled panoramic view, angled-lens views, and close-up zoom-in view provided optical advantages with distinct visualization of the surgical target site. Subsequently, the application of this endonasal endoscopic approach was expanded to the surgical treatment of midline pathologies at the anterior cranial fossa, pterygoid fossa, middle cranial fossa, petrous tip, clivus and posterior cranial fossa as well as for pathologies around the optic nerve and in the cavernous sinus. We report on the history that allowed for the development of the endoscopic endonasal approach to the pituitary and skull base and the personal experience of the senior author developing the technique in the 1990's at the University of Pittsburgh Medical Center [7-21].

\section{Conceptual Development of Endoscopic Endonasal Approach to the Sella}

Ancient Egyptians were the first to utilize a transnasal approach to the skull base and intracranial structures in order to empty the cerebral vault during the mummification process [22] Hermann Schloffer was the first to report a successful transsphenoidal approach for resection of a pituitary adenoma 
1907 [23]. Schloffer utilized a superior nasal route via a transfacial lateral rhinotomy incision which led to complications of meningitis and disfiguring cosmesis. Subsequent surgeons attempted to improve on the technique utilizing various incisions and evolving to the use of a sublabial gingival incision by Halstead, Cushing, Dott, Guiot, and Hardy [4]. The use of the endonasal pathway itself was initially reported in 1910 by Oskar Hirsch who performed his first pituitary surgery in Vienna by approaching the sella through an endonasal route using multiple staged sinonasal operations with visualization with the naked eye $[4,24]$. Despite his first endonasal transsphenoidal surgery having been a reported success, Hirsch subsequently converted to a transseptal submucosal approach, most likely due to fear of surgical infection through such a wide communication made between the nasal and the cranial cavity.

During the same time as Hirsch was developing his technique, Harvey Cushing was developing his own techniques for a transsphenoidal approach for the surgical resection of pituitary tumors. Cushing utilized Schloffer's technique but later modified it to use Halstead's sublabial incision and Kocher's submucosal septal resection [25]. Cushing used the transsphenoidal approach between 1910 and 1925 to operate on 231 pituitary tumors. But his intense interest in transcranial surgeries led to him abandoning the approach to pursue the development of transcranial approaches to sellar tumors.

While Cushing abandoned the transsphenoidal approach, his pupil, Norman Dott, continued to utilize the procedure in England. By 1956, Dott had performed 80 consecutive transsphenoidal operations with no deaths and had also developed a lighted speculum retractor to improve illumination to the surgical site. Dott subsequently introduced his surgical method to Gerard Guiot, a French neurosurgeon who enhanced surgical accuracy by using intraoperative radioflouroscopy to clearly define the anatomy of the nasal passages while maneuvering instruments. In Europe, the transsphenoidal approach continued to evolve [4].

Revival of the transsphenoidal approach in the United States occurred in the 1970's. Jules Hardy from Montreal worked as a fellow under Guiot and learned his methods. In 1967, Hardy introduced the use of the operating microscope for this procedure [4]. At that point, technology was developing and the sublabial transphenoidal surgery adopted the use of the operating microscope for visualization. The sublabial transseptal microscopic pituitary surgery became the gold standard surgical procedure until an endonasal route was revisited. Griffith and Veerapen performed an endonasal approach in 1987 with the insertion of a transsphenoidal retractor through the natural nasal airway to the sphenoid rostrum for microscopic pituitary surgery [6]. This approach was reaffirmed by Cooke and Jones in 1994 [5]. They reported the lack of sinonasal and dental complications when this route was adopted for microscopic pituitary surgery. This revival of the endonasal approach to the sella turcica as well as technological advances allowed for the big leap of utilizing the endoscope for easy access to the pituitary as well as expanding the concept to other regions of the skull base.

Another major advance that stimulated the use of an endoscope in pituitary surgery was the development of endoscopic functional sinus surgery. With the development of a Hopkin's rod-lens endoscope in 1960, Walter Messerklinger, Heinz Stammberger, and David Kennedy progressively refined endoscopic endonasal surgery for sinus disorders. Endoscopic sinus surgery rapidly replaced conventional sinus surgery, given that sinonasal endoscopy brought about radical changes in the concepts of pathophysiology and treatments of sinonasal ailments. Rather than stripping the infected sinus mucosa as it had been done conventionally, endoscopic sinus surgery aimed to restore the physiologic mucous drainage by merely eliminating obstructive pathoanatomy. This came to be called "functional endoscopic sinonasal surgery" [2,3].

As the otolaryngologist quickly adopted endoscopy for sinonasal surgery, endonasal access to the pituitary was appearing to be more feasible then it had been in Hirsch's time with the development of endoscopy. Naturally, interest arose in the use of endoscopy for transphenoidal surgery with the advances in sinonasal endoscopy. However, endoscopic functional sinus surgery was performed mostly at the lateral wall of the nasal cavity while access to the pituitary was better approached with a paraseptal route rather than the middle meatal route [15].

\section{Clinical Application of Endoscopic Endonasal Pituitary Surgery at the University of Pittsburgh Starting With Fresh Cadaver Work in 1991 and Patient Operation In 1993}

With the revitalization of an endonasal route to the pituitary and the established technique of functional endoscopic sinus surgery, HD Jho decided to explore endoscopic pituitary surgery in 1991. He borrowed an endoscope system from Codman and started to work on the approach in a fresh cadaver in 1991. This allowed for him to determine that it was indeed a feasible and practical approach. In addition, he noted the advantages of the endoscope over the microscope quickly such as the slender physique of the endoscope and various optical advantages. Four millimeter rod-lens endoscope was adopted for primary visualization during pituitary surgery since it provided the clearest video images. The basic endoscopes adopted at the time were four millimeter rod-lens endoscopes with $0-$, $30-$, or 70-degree lenses. Firstly, the slender physique of the endoscope shaft with the visualizing lens at the tip allowed for navigation through narrow anatomical spaces and eliminated the need to traumatically retract normal anatomical structures for a surgical corridor. Surgical incision, septal mucosal dissection, or removal of the nasal septum was unnecessary utilizing the endoscopic endonasal transsphenoidal approach. Endoscopic navigation allowed for visualization of the skull base easily from the base of the anterior fossa down to the craniocervical junction at the nasopharynx with only small changes in the angle of the 


\section{Global Journal of Otolaryngology}

endoscope position. Endoscopy opened up a whole new world to access the skull base with no surgical incision and minimizing the morbidity of surgery without the limitations of access seen with the microscope.

The optical advantages of the endoscope over the operating microscope were immediately obvious and amazing. Whereas the microscope provides a magnified view of a limited portion of the sella through a narrow corridor revealed by the transsphenoidal retractor, the endoscope physically enters the sphenoid sinus and provides a wide-angled panoramic view with zooming capabilities. The operating microscope renders a tubular parallel beam view whereas the endoscope shows a diverging flask-shaped, wide-angled view. This wide-angled panoramic view is particularly useful for pituitary tumor surgery because it allows for excellent anatomical visualization at the posterior wall of the sphenoid sinus. A well-known pituitary surgeon from Germany visited HD Jho and was amazed at the endoscopic view of the posterior wall of the sphenoid sinus while observing a live case. He stated that for the first time in his life, he was able to see the carotid artery protuberances and carotid arteries next to the pituitary gland under direct surgical visualization. This wide view demonstration of the posterior wall of the sphenoidal sinus and direct visualization of anatomical structures during the approach eliminated the need for C-arm fluoroscopy for localization that was used during microscopic surgery.

Other optical advantages of the endoscope are an angledlens view that provided direct visualization around anatomical corners such as the suprasellar area or towards the cavernous sinus and the close-up magnified internal view. Angled views allow for direct surgical access with minimal anatomical disturbance to such areas as the pterygoid fossa, anterior cranial fossa, optic nerve, petrous tip, clivus, posterior cranial fossa, and the cavernous sinus. When tumor resection is accomplished, the endoscope can be advanced into the sella or suprasellar area. This close-up magnified view in liaison with zooming of the camera enhanced the magnification of the surgical site. When a 30-degree angled endoscope is inserted into the cavity and rotated through a full revolution, the entire circumference of the cavity can be visualized.

Although rhinologists often use one hand to hold the endoscope and the other hand for surgical instruments, neurosurgical maneuvering requires two hands in order to delicately deal with the pathology around critical structures. HD Jho created a manual endoscope holder so that a surgeon could use two hands continually. He also improvised surgical instruments in order to accommodate and maneuver through a narrow and long surgical corridor. However, as a neurosurgeon, the endoscopic tower and equipment were not available for him to use when he initially tried to utilize this technique to treat his patients. At the University of Pittsburgh Medical Center during this time, the endoscopic system was under the otolaryngologist's domain. Ricardo Carrau was an otolaryngology skull base surgeon at the institute and was open-minded to a partnership in developing this technique. Luckily for Jho and Carrau, they had very supportive and innovative clinical leaders including Professor Peter Jannetta in the Department of Neurosurgery and Eugene Myer in the Department of Otolaryngology. They were encouraged to attempt novel surgical developments without much hinderance. HD Jho initially began by inserting the endoscope during microscope surgery for the first four patients. Eventually, the first endonasal endoscopic transphenoidal surgery was performed on a 45-year old male with a nonfunctioning macroadenoma. The operation was performed on September 25, 1993. Postoperatively, the patient did very well. He stayed in a regular room of the hospital overnight and was discharged the next day.

While performing endoscopic endonasal surgery for pituitary adenomas, HD Jho discovered that this approach also allowed for easy surgical access to the anterior skull base, pterygoid fossa, optic nerves, cavernous sinuses, petrous tip, clivus, and craniocervical junction at the nasopharynx. The endonasal navigation provided tremendous freedom in accessing the skull base with a small change in angle of the endoscope. HD Jho continued to progressively explore access to the midline skull base, but his adventures were not always met with the encouragement and acceptance that his mentors showed.

\section{Dfficulty in Publications}

When HD Jho had utilized this technique successfully in 15 patients, he tried to report on the technical nuances and clinical outcomes. He initially performed a literature search and found a case series of three patients by Jankowski et al published in Laryngoscope [26]. To add to the literature, the experiences of the 15 cases were summed up and submitted to various neurosurgery journals, but repeatedly, the case series was rejected. As the case numbers increased, they continued to add number of cases to their case series and continued submitting for publication in neurosurgery journals to no avail. Meanwhile, Rengachary invited HD Jho to describe the technique for the Neurosurgical Operative Atlas in the chapter for endoscopic pituitary surgery in 1996 [13]. With repeated rejections from neurosurgery journals, Carrau suggested trying an otolaryngology journal with his name listed first. Their first paper was accepted to the Laryngoscope [27]. Their next case series of 45 patients was submitted to Acta Neurochir (Wien) but was told by the editor that the title had to be changed from "endoscopic transsphenoidal surgery" to "endoscopic-assisted transsphenoidal surgery". Although it was not endoscopic-assistance to microscopic surgery, the title was changed in order to disseminate the information and was published in 1996 [14].The original case series of 15 cases was finally published in Surgical Neurology in January 1997 [17]. The Journal of Neurosurgery then published the next case series of 50 patients in 1997 [15].

As their experience grew, Jho and Carrau discovered that the approach allowed for easy access to the midline skull base from 
the anterior fossa, cavernous sinus, optic nerve, pterygoid fossa, petrous tip, clivus, and craniocervical junction. The reported the first case report of utilizing the endoscopic endonasal approach for a clival chordoma in 1997 [16]. Access to the anterior skull base, cavernous sinus, and clivus were reported in three separate submissions to the Minimally Invasive Neurosurgery journal in 1997. Although they each had been accepted immediately, their publications were unexpectedly delayed due to an editor's mistake delaying their publication until 2004 [28-33].

\section{Breaking Up the Team and Starting to Work Alone}

Once the procedure had been published in Laryngoscope, HD Jho and Carrau were invited to talk at the Annual Convention of American Academy of Otolaryngology-Head and Neck Surgery national meeting held in Washington, DC in September, 1996. Carrau spoke first and was followed by a question and answer session before HD Jho's talk. In the audience, many of the otolaryngologists raised their hands to ask "why do we need a neurosurgeon for this surgery". HD Jho spent his time explaining that the operation was for a type of brain tumor and that the nasal corridor is simply a conduit to access the tumor. After his experience at the national meeting, HD Jho decided to start performing the surgeries without the assistance of Carrau.

When performing the procedure alone, HD Jho realized that there had been unnecessary traditional routines in otolaryngology practice such as the use of local infiltration of vasoconstrictors, postoperative nasal packing, and a few days of postoperative oral antibiotics. He eliminated the use of local vasoconstrictor and discovered that his patients developed much less postoperative nasal bloody discharge. This is due to the fact that the vasoconstrictor effect wears off after surgery leading to more bleeding. In addition, nasal packing with a small amount of Telfa was or other material was often used to minimize postoperative nasal bleeding and to prevent adhesion between the nasal septum and middle turbinate. By eliminating this practice, HD Jho noted that his patients were much more comfortable postoperatively. To this day, HD Jho continues to operate alone for endoscopic endonasal pituitary and skull base surgery even after he moved from the University of Pittsburgh Medical Center to Allegheny General Hospital in December of 2001.

\section{Propagation of the Endoscopic Endonasal Pituitary and Skullbase Surgery}

As the endoscopic endonasal pituitary surgery technique began to gain attention, HD Jho was invited to give presentations around the world gaining attention from several neurosurgeons interested in learning the technique. Professor George Tindall in Emery University personally invited HD Jho to the 6th European Workshop on Pituitary Adenomas in Berlin, Germany held in July 1996. His personal invitation was by a call in April 1996 when the program was already well-established. Several hundreds of pituitary neurosurgeons were gathered from the world. The endoscopic pituitary surgery presentation was given with a video clips; however, video display was incomplete due to the different European video system. Then, several neurosurgeons were very much interested in and among them was Paolo Cappabianca from Naples, Italy. He personally inquired various details after the session. Subsequently, he and his team were able to develop this technique [30,29].

Then, Paolo Cappabianca and Enrico de Divitiis attended the 4th International Meeting on Neuroendoscopy and Allied Technology in Marburg, Germany for further inquiry on this subject in March of 2000. They sent a fellow, Alexandra Alfieri, to Pittsburgh to learn the technique under HD Jho and she significantly contributed to cadaveric studies expanding the technique [31-33].

When HD Jho's giving a presentation about endoscopic endonasal pituitary surgery in Marburg, Professor Bauer made a comment that Gerard Guiot was the first to attempt endoscopic pituitary surgery in 1963. Unfortunately, the paper was in French and easily missed when searching the English medical literature [28]. HD Jho was able to come across photos of his endoscope and found it to be very bulky and cumbersome, but the intraoperative photos of the posterior wall of the sphenoidal sinus were very vivid and impressive.

HD Jho gave a presentation during a breakfast seminar of the Annual American Association of Neurological Surgeons (AANS) in 1997, but was met with criticism from Jules Hardy on the use of the endoscope. The following year, though, Hardy had changed his position and mentioned that he had attempted using the endoscope earlier in the year. HD Jho continued to give presentations on the approach around the United States and was met with cold indifference on this topic from traditional skull base surgeons. The advent of endoscopic endonasal pituitary surgery was very much delayed for another decade in the United States. As of 2018, half of all pituitary surgeries are performed under endoscopic visualization according to recent statistics, most of them performed by a team of a neurosurgeon and otolaryngologist.

In Asia, neurosurgeons were much more enthusiastic on this topic. HD Jho was invited to the Annual Meeting of Japanese Neurological Surgeons in Osaka in October of 1997 and was invited back annually for subsequent years. A few years later, in the early 2000's, pituitary tumor surgery statistics showed that more than $50 \%$ of pituitary adenoma surgery in Japan was done with the use of an endoscope. HD Jho also carried annual workshops on endoscopic cranial and spine surgery at Gil Hospital in Incheon, South Korea starting in 1998. Annual workshops included demonstrations of live surgery and continued for five consecutive years. On average, 60 Asian neurosurgeons came to the workshop annually and disseminated the endoscopic endonasal pituitary surgery technique rapidly in Asia while microscopic transsphenoidal surgery was still the mainstream in the United States Figure(1). 


\section{Global Journal of Otolaryngology}

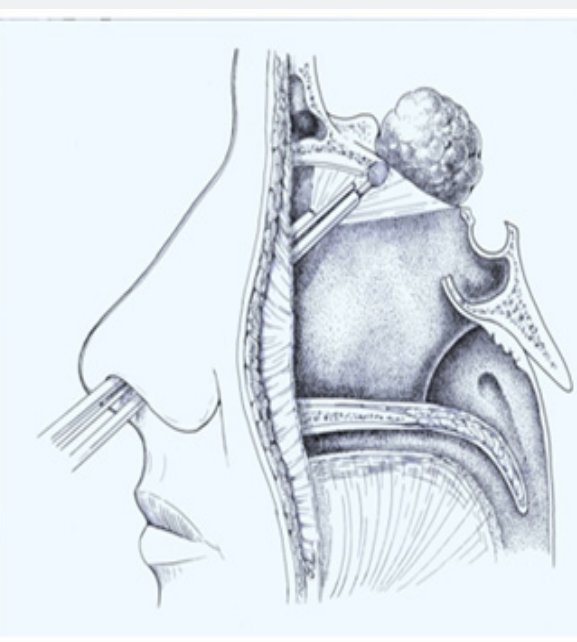

A

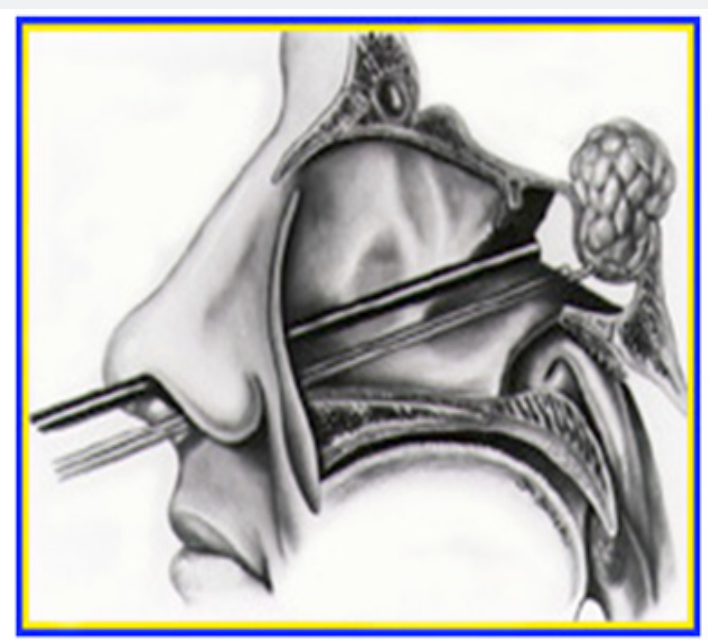

B

Figure 1: These Schematic drawings show endoscopic endonasal approach to a pituitary tumor (A), anterior cranial skullbase (B), and clivus and posterior cranial fossa. We started endoscopic pituitary surgery in 1993; then, soon learned that an endonasal endoscopic approach had an easy access to the skull base from the crista Galli to the craniocervical junction at the nasopharynx.

\section{Future Prospects of Endoscopic Pituitary and Skullbase Surgery}

HD Jho moved his practice from the University of Pittsburgh medical Center to Allegheny General Hospital in Pittsburgh in December of 2001. The team at the University of Pittsburgh Medical Center continued to evolve the technique to become the expanded endonasal technique performed today. Meanwhile, HD Jho converted all of his cranial and spinal surgery to utilize endoscopic techniques. He has not used the operating microscope in his neurosurgery practice for many years. With his passion for technology, HD Jho has visions for future surgery to be performed utilizing an image system produced either by a small external video camera or internal video camera (Videoscope) and even the possibility of robotic surgery. One drawback of the endoscope is that the images have been two dimensional. In late 1990's, HD Jho tried out a 5-mm three dimensional endoscope, which was truly three dimensional as the endoscope tip had two lenses. It showed promise for short surgical procedures less than a one hour. However, if the surgery continued for more than two to three hours, the surgeon got eye fatigue and headaches. Thus, the use of a 3-D endoscope may not be necessary for most cases.

The endoscopic endonasal approach has been proven to provide easy surgical access to the midline skull base from the anterior fossa to the craniocervical junction. In order to prevent cerebrospinal fluids leak, various surgical techniques have been reported. However, the nasal anatomy has to be preserved well and improvements of skull base reconstruction must be developed.

The endoscopic endonasal approach is simply one of the various surgical approaches to the skull base and can be utilized to access the skull base from the anterior fossa to the craniocervical junction. For anterior skull base tumors, transcranial versus endonasal approach has to be chosen case by case. In HD Jho's practice, a transcranial endoscopic approach via a minimally invasive small incision for anterior skullbase surgery is pretty similar to an endonasal approach in terms of invasiveness the patient sustains. Cavernous sinus surgery for pituitary adenomas can be easily and safely performed. Bilateral optic nerve decompression can be performed for benign intracranial hypertension or pseudotumor cerebri if optic nerve decompression is deemed the treatment of choice for worsening vision. For surgical treatment of chordomas and chondrosarcomas of the clivus, the endonasal approach will be the treatment of choice. HD Jho also presented on endoscopic endonasal aneurysm surgery for anterior communicating artery aneurysms, ophthalmic artery aneurysms, cavernous sinus carotid artery aneurysms and vertebrobasilar artery aneurysms demonstrating his technique on cadavers at the annual meetings in Japan in late 1990's. Since then, there have been several reports on clippings of anterior communicating artery aneurysms. Endoscopic endonasal approach to an anterior communicating artery aneurysm does not have to fight against swollen brain.

When this endoscopic endonasal surgery was given to traditional skull base surgeons in 1990's, they severely criticized HD Jho and insisting that radical surgery was required such as a face-splitting procedures or an extensive fronto-temporal skull base surgery. Their criticism was so harsh that HD Jho decided not to attend skull base surgery meetings for many years. But, time has proven that they were wrong. Over almost three decades, tremendous advances have been made in endoscopic endonasal pituitary and skull base surgery.

\section{Conclusion}

The personal journey on the endoscopic endonasal pituitary and skullbase surgery in early 1990's at the University of Pittsburgh Medical Center is reported. 


\section{Global Journal of Otolaryngology}

\section{References}

1. Dandy WE (1944) An operative procedure for hydrocephalus. Johns Hopkins Hosp Bull 33:189-190.

2. Stammberger H (1986) Endoscopic endonasal surgery concepts in treatment of recurring rhinosinusitis. Part II. Surgical technique. Otolaryngol Head Neck Surg 94(2): 147-156.

3. Tajudeen BA, Kennedy DW (2017) Thirty years of endoscopic sinus surgery: What have we learned? World J Otorhinolaryngol Head Neck Surg 3(2): 115-121.

4. Landolt AM (1996) History of transsphenoidal pituitary surgery. In: Landolt AM, Vance ML, Reilly PL (eds): Pituitary Adenomas. New York: Churchill Livingstone pp. 307-314.

5. Cooke RS, Jones RAC (1994) Experience with the direct transnasal transsphenoidal approach to the pituitary fossa. Br J Neurosurg 8 193-196.

6. Griffith HB, Veerapen R (1987) A direct transnasal approach to the sphenoid sinus: Technical note. J Neurosurg 66(1): 140-142.

7. Jho HD (1997) Endoscopic endonasal pituitary surgery: Technical aspects. Contemporary Neurosurgery 19(6): 1-7.

8. Jho HD (2001) Endoscopic transsphenoidal surgery. J Neurooncology 549(2): 187-195.

9. Jho HD (2001) Endoscopic endonasal approach to the optic nerve: A technical note. Minim Invas Neurosurg 44: 190-193.

10. Jho HD (2001) Expanding role of endoscopy in skull base surgery. Clin Neurosurg 48: 287-305.

11. Jho HD, Alfieri A (2000) Endoscopic transsphenoidal pituitary surgery: Various surgical techniques and recommended steps for procedural transition. Br J Neurosurg 14(5): 432-440.

12. Jho HD, Alfieri A (2001) Endoscopic endonasal pituitary surgery: Evolution of surgical technique and equipment in 150 operations. Minim Invas Neurosurg 44: 1-12.

13. Jho HD, Carrau RL, Ko Y (1996) Endoscopic pituitary surgery in Wilkins RH, Rengachary SS (eds): Neurosurgical operative atlas. Williams \& Wilkins 5(1): 1-12

14. Jho HD, Carrau RL (1996) Endoscopy assisted transsphenoidal surgery for pituitary adenoma. Technical note. Acta Neurochir (Wien) 138(12) 1416-1425

15. Jho HD, Carrau RL (1997) Endoscopic endonasal transsphenoidal surgery: Experience with 50 patients. J Neurosurg 87(1): 44-51.

16. Jho HD, Carrau RL, Mclaughlin ML, Somaza SC (1997) Endoscopic transsphenoidal resection of a large chordoma in the posterior fossa: Acta Neurochir (Wien) 139(4): 347-348.
17. Jho HD, Carrau RL, Ko Y, Daly M (1997) Endoscopic pituitary surgery: An early experience. Surg Neurol 47(3): 213-222.

18. Jho HD, Ha HG (2004) Endoscopic endonasal skull base surgery: Part 1. The midline anterior fossa skull base. Minim Invas Neurosurg 47(1): $1-8$

19. Jho HD, Ha HG (2004) Endoscopic endonasal skull base surgery: Part 2. The cavernous sinus. Minim Invas Neurosurg 47: 9-15.

20. Jho HD, Ha HG (2004) Endoscopic endonasal skull base surgery: Part 3. The clivus and posterior fossa. Minim Invas Neurosurg 47(1): 16-23.

21. Jho HD, Park IS, Alfieri A (2000) The future of pituitary surgery. Clin Neurosurg 47: 83-98.

22. Fanous AA, Couldwell WT (2012) Transnasal excerebration surgery in ancient Egypt. J Neurosurg 116(4): 743-748.

23. Schloffer H (1907) Erfolgreiche operation eines hypophysentumors auf nasalem wage. Wien Klin Wochenschr 20: 621-624.

24. Hirsch $O$ (1910) Endonasal method of removal of hypophyseal tumors. With a report of two successful cases. JAMA 55: 772-774.

25. Cushing H (1912) The pituitary body and its disorder: clinical states produced by disorders of the hypophysis cerebri. Philadelphia: JB Lippincott 1912: 296-305.

26. Jankowski R, Auque J, Simon C, Marchal JC, Hepner H, et al. (1992) Endoscopic pituitary tumor surgery. Laryngoscope 102(2): 198-202.

27. Carrau RL, Jho HD, Ko Y (1996) Transnasal transsphenoidal endoscopic surgery of the pituitary gland. Laryngoscope 106: 914-918.

28. Guiot G, Rougerie J, Fourestler A (1963) Une nouvelle technique endoscopique: Exploration endoscopiques intracraniennes. Presse Med 71: 1225-1228.

29. De Divitiis E, Cavallo LM, Cappabianca P, Esposito F (2007) Extended endoscopic endonasal transsphenoidal approach for the removal of suprasellar tumor: part 2. Neurosurgery 60(1): 46-58

30. Capppabianca P, Alfieri A, de Divitiis E (1998) Endoscopic endonasal transsphenoidal approach to the sella: Towards functional endoscopic pituitary surgery (FEPS). Minim Invasive Neurosurg 41(2): 66-73.

31. Alfieri A, Jho HD, Tschabitscher M (2002) Endoscopic endonasal approach to the ventral cranio cervical juncture: anatomical study. Acta Neurochir (Wien) 144: 219-225.

32. Alfieri A, Jho HD (2001) Endoscopic endonasal approach to the cavernous sinus. Surgical approaches. Neurosurgery 49: 354-362.

33. Alfieri A, Jho HD (2001) Endoscopic endonasal approach to the cavernous sinus. An anatomic study. Neurosurgery 48: 827-837.

\section{Your next submission with Juniper Publishers will reach you the below assets}

- Quality Editorial service

- Swift Peer Review

- Reprints availability

- E-prints Service

- Manuscript Podcast for convenient understanding

- Global attainment for your research

- Manuscript accessibility in different formats

( Pdf, E-pub, Full Text, Audio)

- Unceasing customer service

Track the below URL for one-step submission https://juniperpublishers.com/online-submission.php 